\title{
EXAMINING THE ROLE OF SUPPORT FOR CREATIVITY IN DETERMINING CREATIVITY; MEDIATING ROLE OF EPISTEMIC CURIOSITY AND MODERATING ROLE OF TRUST IN LEADERSHIP
}

\author{
SARAH ZAFAR \\ Capital University of Science and Technology, Islamabad, Pakistan
}

\begin{abstract}
The current study examined the role of support for creativity in determining creativity with the mediating role of epistemic curiosity and moderating role of trust in leadership. Data were collected from 321 employees working in telecom sector of Pakistan situated in Rawalpindi, Islamabad, Sialkot and Lahore. Regression analysis suggested that support for creativity is positively associated with creativity and epistemic curiosity, whereas, there is a positive relationship between epistemic curiosity and creativity. Epistemic curiosity further mediates the relationship between support for creativity and creativity of employees, while trust in leadership moderates the relationship between Support for creativity and creativity of employees. Results are discussed in the light of existing environment in the private sector organizations of Pakistan. The paper concludes by discussing study limitations and future research directions.
\end{abstract}

\section{INTRODUCTION}

Globalization has its virtues in making business for organizations easier than ever, however, there is also a second side to that coin. In the current era of globalization and the access of information, an organization's success is dependent upon their creative endeavors. Moreover, it also provides a competitive advantage to the organization in this highly competitive market (Imante, 2013). Due to the complex and ever changing environment, managers and leaders can't just rest on their laurels as there can be another organization that creates something new (Haserot, 2011). This has resulted in creativity being seen as a crucial core competence for these organizations. Consequently, creativity is perceived as an organizational resource that should be encouraged (Kent, 2007).

Creativity is the production of new and novel idea, which is original and practical. There is a constant search for employees who take an interest in creative ideas that are a stepping stone for innovative and better products (Simmons, 2012). For the organizations the competitive advantage is the thing that can make or break the organization's bottom line. Previously, competition meant making products better in quality and low in cost. However, that is not enough for the present market. Now new and efficient strategies need to be implemented to get ahead in the market. Therefore, organizations must be willing to embrace change in order to create a competitive advantage for them and to maintain it as well (Amabile, 1985). Consequently, it is suggested that creative ideas are the product of intrinsic motivation rather than extrinsic (Amabile, 1996). Furthermore, it is stated that many different elements affect a person's creativity, which include personality, leadership, social environment, and working environment.

Support for creativity refers to the extent to which supervisors and coworkers encourage employees to develop creative ideas. Support for creativity from supervisors and coworkers encourage employees and assist them so that they might be fully motivated not only to find solutions to problems (Tierney \& Farmer, 2004) but also help employees to think out of the box for more efficient strategies (Scott, 1994). Supporting creativity in the organization also shows that their employees' creative ideas and activities are appreciated and valued by the organization (Ford, 1996). Previous studies have also shown that support for creativity is positively associated with employee's creativity (Shalley, 2004). An organization's culture also supports or impedes the employees' creativity.

Very limited literature is available where epistemic curiosity has been tested as mediator between support for creativity and creativity of employee. Epistemic curiosity is the outcome of support for creativity and antecedent of creativity of employee. And trust in leadership has not been tested as moderator before in this context. Moreover, there has been a gap in the studies conducted in this domain which pertains to the fact that this model 
has not been tested in the Pakistani culture yet.

The thirst to attain new skills and knowledge and to incite interest cognitively or to eradicate deprivation of information is known as epistemic curiosity (Litman, 2008). The definition also states that the perception of lack of knowledge gives rise to curiosity (Loewenstein, 1994). Curiosity has directed many studies (Berlyne, 1954) to research the science behind it (Berlyne, 1960). It has been observed that creative solutions (Litman, 2008) are more likely to be explored by the people who have the traits of epistemic curiosity in abundance (Mussel, 2013).

Trust has been defined as the expectation that the other person fulfills their commitment to the actions promised and the belief that they will follow through with having no control over their actions as well (Mayer, Davis, \& Schoorman, 1995). Trust in leadership, in other words, is a form of relational trust that derives from participation (Aryee, 2002) of both leader and the subordinate in the Leader-Follower relationship (Wiggins, 1997). The trust in leadership motivates employees to be more confident in their leader's capabilities. Hence, trust is the tool that assists in effective management by the leader (McCauley, 1992). It is implied that leader's creativity also enhances employee's trust in their leadership (Bass, 1993). Another aspect of the definition of trust is that it is as psychological as it is intentional. Support from one's organization can also influence them to reciprocate with trust in their leadership (Kramer, 1999).

The organizations across the world are recognizing the need for supporting creativity to encourage their employees to be innovative. However, Pakistan's culture and organizational conditions are completely distinctive as compared to developed countries. The telecom sector in Pakistan is one of the fastest growing industries. Even with all the support and research relating to creativity in workplace, creativity is still in the initial stages of acceptance (Amabile, Barsade, G, Mueller, S, \& Staw, 2005). Moreover, the organizational structure in Pakistan is still in the process of transitioning from centralized to a flatter hierarchal pyramid. This centralization of power discourages employees' involvement in the activities as well as their creative inputs. Consequently, in Pakistan, creativity at workplace has not yet been completely exercised due to less employee empowerment. This results in lack of confidence among employees to present their creative ideas to their superiors.

Existing literature on support for creativity and creativity of employees has already been established, but the mediation of epistemic curiosity and moderation of trust in leadership has not been examined before. Moreover, this study has not been tested before in the culture of Pakistan. This study is piloted to test the effect of support for creativity on creative employees and how much trust do they put in their supervisors since it's a collectivistic society and also to examine the level of supervisor's support to their subordinates on being creative.

The idea behind this study is that the employees perceive that the supervisor's individual feedback is representative of the organization as a whole (Eisenberger, 1990). Organizational support theory (OST) suggests that the extent of support provided to the employees leads them to form a perception about the organization's attitude towards them. This perception influences the employees' commitment and approach to the organization as a whole (Eisenberger, 1990). The theory provides the base for creativity and support for creativity, i.e. how supportive is organization of employees creative endeavors. It builds the employeeemployer relationship and it also provides the foundation for trust in leadership and epistemic curiosity

\section{LITERATURE REVIEW}

\section{Support for creativity and Employee's creativity}

In an organization, it is required by employees to think creatively for producing new and better products (Moorman, 1997). Previous research has proven a significant relationship between supervisory support and creativity (Amabile \& Gryskiewicz, 1989). The ability to create innovative products (Amabile, 1988) is related to the degree of an employee's creativity (Staw, 1990). This shows the extent to which creative employees are able to perform efficiently (Woodman, 1993), as creative routine helps organizations to respond swiftly (March, 1958) to market demands (Kanter, 1988). Supervisors can support subordinates by providing valuable feedback (Van de Ven, 1986) about their tasks to achieve productivity (Vissers, 2002).

Supervisor's support can help employees to cope (Lubart, 2001) and act proactively to solve these problems creatively (Zenasni, 2008). Employees are motivated to try different approaches to perform their tasks creatively (Hackman, 2002). If employees perceive their jobs are meaningful and important on the basis of useful feedback from supervisors, they will increase creative activities (Yi, 2013). Employees perform their tasks better (Nielsen, 2008) when they exert more effort for the better understanding of a problem by approaching it through various perspectives (Gilson, 2004). Creative outcomes are highly probable when employees receive encouragement from their leaders and they know that they are expected to perform creatively (Amabile, Conti, Coon, Lazenby, \& \& Herron, 1996). Therefore, hypothesis one has been developed based on the aforementioned argument. 
Hypothesis 1. There is a positive relationship between support for creativity and employees' creativity.

\section{Support for creativity and Epistemic curiosity}

The definition of epistemic curiosity states that "it is the aspiration to search, gain and make use of new knowledge" (Berlyne, 1954). To stimulate our cognitive activities (Mussel, 2010) and to reduce scarcity of information (Tuten, 2001), epistemic curiosity is a relevant tool for that (Litman, 2008).

It is suggested that to acquire new expertise (Arnone, 1994), the person has to have epistemic curiosity as a major component of his/her personality (Berlyne, 1954). Additionally, it is also stated as an individual's personal trait (Litman \& Spielberger, 2003). Literature suggests that the link between epistemic curiosity and need for cognition has been established (Mussel, 2010). Some other researches (Olson, 1984) also had their findings aligned with it. The need for cognition is defined as person's ability to be engaged in the thought process (Cacioppo, 1982) and to enjoy it as well; whereas, epistemic curiosity is a need for attaining novel experience (Berlyne, 1960). Curiosity facilitates and promotes learning (Kashdan, Rose, \& Fincham, 2004), which in turn enhances their personal growth.

If creative process is not totally executed (e.g., a problem is misunderstood, not all information is fetched and examined (Redmond, 1993), or too few alternative ideas are generated), the quality of the creative output will suffer (Zhang, 2010). This proposition is in line with leadership-creativity model (Tierney, 2008), which declares that leaders' influence on creativity occurs via the "evolving system" of follower thoughts, drives, and activities in order to predict employee creativity, which in turn helps employees' growth when their creativity is encouraged by their employer (Zhang, 2010).

The rapport of support for creativity and epistemic curiosity has been identified in the past literature. If an employee feels motivated and knows that he has support of his supervisors, he will explore more and be more curious to as how things work or for coming up with a better and improved product.

\section{Hypothesis 2. There is a positive relationship between support for creativity and epistemic curiosity.}

\section{Epistemic curiosity and Creativity}

There is a good reason to an individual's curiosity and creativity, and this can be clearly seen when a person is using an electronic computer, flying in an airplane or listening to a symphony; the results of an individual's creativity are indeed impressive at every level, be it organizational, mechanical or artistic level and seem to have a satisfactory explanation (Leuba, 1958). If we truly want to understand curiosity and creativity, there is only one simple thing that is to be understood i.e. there is existence of need and to fill that up, people find different ways as to how this can be achieved and hence come up with creative ideas.

In an organization, when an employee finds himself stuck in a problem, or if he/she has to come up with a cost cutting idea for maximum profits, he/she becomes curious about the problem and starts thinking of all the possible ways to find the best possible, useful solution of the problem. This goal can be achieved through reasonable amount of supervisory support.

\section{Hypothesis 3.There is a positive relationship between epistemic curiosity and creativity of employee.}

\section{Epistemic curiosity as a mediator}

Litman \& Jimerson, (2004) developed interestdeprivation (I/D) theory of curiosity. They presented the idea that there are two conditions of curiosity, one: person is interested in finding out the answer and two: person has informational deprivation which is causing the curiosity. Like other human desires, curiosity is linked with approach behavior and experiences reward (Berlyne, 1960). Curiosity is considered a positive trait, as when one's curiosity is stimulated, it is intrinsically rewarding and very pleasurable (Day, 1971). However, learning new information may feel satisfactory and rewarding (Peterson C. \&., 2004), because it scatters undesirable state of uncertainty (Kashdan, Rose, \& Fincham, 2004) rather than arousing one's interest (Berlyne, 1954).

In an organization, where there's a supportive climate for employees to participate and come up with new ideas, epistemic curiosity plays an important role and acts as a catalyst between support for creativity from supervisors and creativity of subordinates. Past literature has shown many positive links between support for creativity and creativity of employee.

\section{Hypothesis 4. Epistemic Curiosity mediates the relationship between support for creativity and creativity of employees.}

\section{Trust in leadership as a moderator}

Trust is considered to be mental relation with another person. Past literature defines trust as an individual's 
state of mind, beliefs (McKnight, 1996) and readiness to rely on another individual (McAllister, 1995). Similarly, when an individual trust his supervisor, his confidence in his supervisor is reflected (Chou, 2013). The recent studies have recommended that trust between the leader and their followers is automatically developed if the leadership style is effective which, as a result, enhances overall creativity in employees.

It has been recognized that despite being vulnerable to harm, the trusted can trust the other party due to a expectation that they will not abuse this relation (Rousseau, 1998). Hence, there are two key concepts in trust: vulnerability and positive expectations. Different people have different approaches towards trust, some consider it as cognitive and psychological state while other consider it as choice behavior (Kramer, 1999). Social exchange theory (Blau, 1964) claims that trust emerges with the constant and frequent exchange of ideas and talks; and further benefits the involved individuals. Once the successful exchange is made, it then leads to trust because it shows mutual support and investment in relationship.

The research that was conducted for this study recommended that with a high level of creativity in the subordinate with the addition of trust between them can strengthen the relationship between support for creativity and employees' creativity. The trust mentioned between the employer and the employee is cognition-based, which refers to the fact that rational reasons are being considered (Mayer, Davis, \& Schoorman, 1995), which include reliability and responsibility, competence and integrity to establish this relationship (McAllister, 1995) integrity, competence; (Cook, 1980). Since this trust is created through effective communication amongst the parties, the employees consider their supervisors more competent and dependable (McAllister, 1995). Hence, employees who trust their supervisors are predicted to have a positive reaction when they are strongly supported by their leaders (Parayitam, 2007), because they sense that the better performance is expected from them. The research shows that there are other factors that interact with trust, which in turn influence the reaction between the parties (Goris, 2003) an example of which is cognitive conflict (Ranaweera, 2003).

Being vulnerable is one of the key factors of trust (Butler, 1991) along with the positive perception (Mayer \& Davis, 1999) that there will be a protection of their trust (Rousseau, 1998). And also others intentions (Mayer, Davis, \& Schoorman, 1995), character (Knorr, 1962), reliability and integrity's assessment will be considered (Dirks, 2000). To accept being vulnerable (Butler, 1991), there has to be a well established relationship where both parties reciprocate goodwill (Baier, 1985).

According to functional approach of leadership
(Govier, 1994), the leader has responsibility to manage the needs of his subordinates (Stack, 1988) especially when they are not being handled satisfactorily (Hackman, Walton, \& Goodman, 1986). Antecedents of trust are ability, benevolence, and integrity (Mayer, Davis, \& Schoorman, 1995). Outcomes of trust are: behavioral (Schoorman, 2007) and performance outcomes, job attitudes (Gill, 2005) and intentions, and correlates (Kozlowski, Gully, Nason, \& Smith, 1999).

\section{Hypothesis 5. Trust in leadership positively moderates the relationship between support for creativity and employees' creativity.}

\section{THEORETICAL FRAMEWORK}

\section{FIGURE 1}

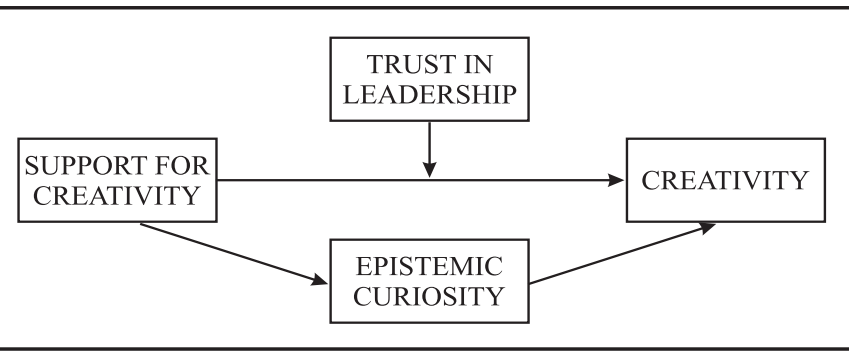

\section{METHODOLOGY}

\section{Sampling}

The current study is a cross sectional study of a descriptive nature, which used the survey method to collect the data. Convenient sampling technique was used in order to draw the sample. 350 questionnaires were distributed in different cities of Punjab, 326 questionnaires were received, out of which 321 were usable. Thus, the response rate was $93 \%$. The data for this study were collected over the span of five weeks. The organizations from where the data were collected consisted of the telecom sector and advertising agencies of Pakistan (Ufone, Mobilink, Telenor, Warid, SNL, WiTribe and AdcomPvt Ltd).

The study used age, tenure, gender and qualification as the control variables. The data collected from the telecom sector shows that $9.3 \%$ of the employees are less than $25 y$ years old; whereas, $64.2 \%$ of the data consists of 26-33years old employees. Additionally, $26.2 \%$ employees lie in the category of 34-41years of age. Thus the 41 and above category consists of a small number of employees. The employees with 0-5years of experience cover $25 \%$ of sample. Whereas the $6-10$ years of experience category consists of $75.1 \%$ of the sample the 11-15 years experience consisted of $21.8 \%$ of the sample and the employees with 15 or more years 
of experience amounted to a very small percentage of sample. The gender demographics were such that the male respondents were $82.6 \%$ of the sample, whereas the rest i.e. $16.5 \%$ were female. In the education category, the percentage of respondents that had completed their masters was $32.4 \%$; while the majority of the sample i.e. $64.2 \%$ respondents selected bachelors and $6 \%$ of the respondents selected intermediate.

\section{Instrumentation}

5-point Likert scale was used in the questionnaire where 1 represented strongly disagree and 5 represented strongly agree.

\section{Support for creativity}

Support for Creativity was measured by 2 items scale developed by (Madjar, 2002). The sample items include "My [supervisor] support experimentation with new methods and ways of doing things", "My coworkers discuss my work-related ideas with me in order to improve them."

\section{Creativity}

Creativity was measured by 13 items scale developed by (Zhou, 2001). The sample items included "I suggest new ways to achieve goals or objectives", "I suggest new ways to increase quality", "I am not afraid to take risks."

\section{Epistemic Curiosity}

Epistemic curiosity was measured by 10 items scale developed by (Mussel, 2013). The sample items include "I am interested in how my contribution impacts the company", "I enjoy developing new strategies, regarding practical problems", "I'm also interested in the underlying theory, when confronted with complex problems", "I like to look for new solutions, I enjoy pondering and thinking".

\section{Trust in leadership}

Trust in leadership was measured by 6 items scale developed by (Podsakoff, 1990). The sample items include "I feel quite confident that my leader will always treat me fairly", "I feel a strong loyalty to my leader", "I have a strong sense of loyalty toward my leader."

\section{RESULTS}

The data were analyzed using correlation and regression analyses, in order to test the hypotheses. Table (1) shows the results of correlation analysis along with the mean and standard deviation of each variable.

TABLE 1

Correlation Analysis, Mean, Standard Deviation and Reliability

\begin{tabular}{|c|c|c|c|c|c|c|c|}
\hline & Variables & Mean & SD & 1 & 2 & 3 & 4 \\
\hline 1 & Support for creativity & 3.32 & 0.87 & 1 & & & \\
\hline 2 & Epistemic curiosity & 3.79 & 0.45 & $.362 * *$ & 1 & & \\
\hline 3 & Creativity & 3.75 & 0.43 & $.288 * *$ & $.512 * *$ & 1 & \\
\hline 4 & Trust & 3.55 & 0.57 & $.357 * *$ & $.471 * *$ & $.549 * *$ & 1 \\
\hline
\end{tabular}

Table 2

Moderated-Mediated Regression Analysis

\begin{tabular}{lcccc}
\hline \multicolumn{1}{c}{ Variables } & $\boldsymbol{\beta}$ & SE & T & P \\
\hline Path a: IV to DV & .18 & .02 & 6.92 & .00 \\
Path b: M to DV & .84 & .02 & 3.62 & .00 \\
Path c: IV to DV (with mediator) & -.15 & .07 & -2.2 & .02 \\
Int_1 (SC*TL) & .03 & .01 & 1.61 & .10 \\
& \multicolumn{2}{c}{ LL 95\% CI } & \multicolumn{2}{c}{ UL 95\% CI } \\
Bootstrap Results for indirect effect & \multicolumn{2}{c}{.12} & & \\
\hline
\end{tabular}


The mean value of support for creativity is 3.32 and standard deviation is 0.87 . The mean value of epistemic curiosity is 3.79 and standard deviation is 0.45 . The mean value of creativity is 3.75 and standard deviation is 043 . Similarly, the mean of trust in leadership is 3.55 and standard deviation is 0.57 . The smaller value indicates the positive impact they have, whereas greater values show the negative effect among the variables. Table (1) further indicates that Support for creativity is positively and significantly correlated to employee creativity $(\mathrm{r}=$ $-.288 * * \mathrm{p}<0.05)$ and Epistemic Curiosity $(\mathrm{R}=.362 * * \mathrm{P}$ $<0.05)$. However, Epistemic curiosity is positively and significantly correlated with employee creativity $(\mathrm{r}=$ $.512 * * \mathrm{P}<0.05)$ Support for creativity is positively and significantly correlated with trust in leadership as well ( $\mathrm{r}$ $=.357^{* *} \mathrm{p}<0.05$ ), while Epistemic curiosity is positively and significantly associated with trust in leadership ( $\mathrm{r}$ $=.471^{*} * \mathrm{P}<0.05$ ), along with the significant positive correlation between Employee Creativity and trust in leadership $\left(\mathrm{r}=.549^{* *} \mathrm{p}<0.05\right)$.

\section{Regression Analysis}

In order to test the hypotheses, regression analysis, using Preacher and Hayes method (2008). The table (2) shows the results of the moderated-mediated regression analysis.

Table (2) shows the results of regression analysis. The findings suggest that support for creativity is positively and significantly related to the employee creativity with $p=0.00$ and $t$ value at 6.92 , leading to the acceptance of hypothesis one. Similarly, as per the results, epistemic curiosity partially mediates the relationship between support for creativity and creativity at $p=0.02$, as indicated by path $c$; thus leading to the acceptance of hypotheses two, three and four.

Results of the moderation as given in table (2) indicate that trust in leadership does not positively moderate the relationship between support for creativity and creativity, with $\mathrm{p}=.10$ and $\mathrm{t}$ value at 1.61 . The hypothesis five suggested that trust in leadership would further strengthen this positive relationship between support for creativity and creativity, but as regression results, the moderation hypothesis has been rejected.

\section{DISCUSSION AND CONCLUSION}

The results of the regression analysis in the previous section indicated that all the proposed hypotheses of the study have been substantiated, meeting the study objective. Findings suggest that support for creativity among employees is positively and significantly associated with the creativity of the employee. When creativity of employees is being supported by his supervisor, it enhances his overall creativity because support itself is a big motivator. The results are in line with the existing literature; when employees receive support from their supervisors and co-workers', they tend to perform better and come up with creative solutions to the existing problem.

Furthermore, the results indicated that there is positive relationship between epistemic curiosity and employee's creativity. Curiosity opens doors of unlimited ideas, which lead to creative problem solving. Existing literature supports the result establishing that when employees are curious, they explore all the options available for the current problem and decide the best possible solution. Similarly, epistemic curiosity partially mediates the relationship between support for creativity and creativity, as supported by the literature; whereas, the rejection of moderation hypothesis can be justified through the contextual element. Subordinate's creativity and high level of cognition-based trust in their supervisor strengthens the relationship between support for creativity and creativity of employee. But in Pakistan's culture, where there is high power distance, uncertainty avoidance and centralized organizational environment, turns out that subordinates don't feel comfortable trusting their supervisors, which rejects our proposed hypothesis.

The current study was conducted in the telecom sector of Pakistan to confirm whether there is a relationship between support for creativity and employees' creativity. IT firms and advertising agencies of Rawalpindi and Islamabad were tested with the questionnaire to confirm the validity of this relationship in the telecom sector where the culture comprises of high power distance and the lack of trust in leadership. Moreover, the selected mediator which is epistemic curiosity confirmed its mechanism in this relationship, in the context of telecom sector of Pakistan. Support for creativity and employees' creativity was also substantiated. The results confirmed the positive correlation between epistemic curiosity and creativity of the employees. Also, trust in leadership was used as the moderator to check the relationship between support for creativity and creativity of employees. Trust in leadership did not moderate the relationship, as proposed, leading to give way to the contextual factor in the study. People find it hard to trust, and hence mostly replied negatively when they were asked about trusting their leaders. Thus, the application of the model that was created for this study is relevant to this research context. One of the main findings of the current study is that trust in leadership is an integral component of the leaderfollower relationship. 


\section{RECOMMENDATIONS}

For a developing country like Pakistan, there needs to be a growth in industry and organizations. For this purpose, it is vital for supervisors to focus on empowering their employees through supporting their creativity and epistemic curiosity. The telecom sector is facing the toughest competition in the industry as well as a lot of problems due to the politics, psychological contract breaches and low self-esteem. Thus, it is recommended that the telecom organizations instigate in their employees to support their subordinates, when appropriate. This will help in empowering them and instigating a sense of belonging and loyalty to the organization and their supervisor, leading the organization towards an era of growth and success.

\section{LIMITATIONS}

The study was designed and executed with the determination to avoid any flaws however some were still found. Those limitations are mentioned below. First of all, the sample size was comparatively smaller due to the time constraints. Secondly, as the organizations from which the data were selected are located in the twin cities and two other in Punjab, Pakistan. It might not be the accurate representative ofthewholepopulation, whereas, employees working in different cities exhibit different behavior due to different subcultures as well. Third limitation was present due to the data being collected from the creative departments of only telecom companies. Therefore, this study cannot be generalized to other industry's creative departments. And another limitation was the scales used in the present study were self-reported, in measuring the attitudinal aspects of respondents the self-reported data are mostly recorded biased.

\section{FUTURE DIRECTIONS}

The impact of different cultures can be explored in future studies to provide a cross-cultural comparison. Countries like United States and China can be used to compare the findings from this study. Current study investigated the mediating role of epistemic curiosity. In the future this variable can be used as an independent or dependent variable along with rest of the same variables. Researchers can also add more variables as outcome of breach of psychological contract and develop a comprehensive model to know how breach of psychological contract effects on its outcomes.

\section{REFERENCES}

Amabile, T. M. (1985). Motivation and

creativity:
Effects of motivational orientation on creative writers. Journal of Personality and Social Psychology, 48(2), 393-399.

Amabile,T.M.(1988).Amodel of creativity and innovation in organizations. Research in Organizational Behavior, 10(1), 123-167.

Amabile, T. M. (1996). Creativity in context: Update to" the social psychology of creativity.". Westview press.

Amabile, T. M., \& Gryskiewicz, N. D. (1989). The creative environment scales: Work environment inventory. Creativity Research Journal, 2(4), 231-253.

Amabile, T. M., Barsade, S. G., Mueller, J. S., \& Staw, B. M. (2005). Affect and creativity at work. Administrative science quarterly, 50(3), 367-403.

Amabile, T. M., Conti, R., Coon, H., Lazenby, J., \& Herron, M. (1996). Assessing the work environment for creativity. Academy of Management Journal, 39(5), 1154-1184.

Arnone, M. P., Grabowski, B. L., \& Rynd, C. P. (1994). Curiosity as a personality variable influencing learning in a learner controlled lesson with and without advisement. Educational Technology Research and Development, 42(1), 5-20.

Aryee, S., Budhwar, P. S., \& Chen, Z. X. (2002). Trust as a mediator of the relationship between organizational justice and work outcomes: Test of a social exchange model. Journal of Organizational Behavior, 23(3), 267-285.

Baier, A. (1985). Postures of the mind: Essays on mind and morals (Vol. 11). Minneapolis: University of Minnesota Press.

Bass, B. M. (1999). Two decades of research and development in transformational leadership. European Journal of Work and Organizational Psychology, 8(1), 9-32.

Berlyne, D. E. (1954). A theory of human curiosity. British Journal of Psychology. General Section, 45(3), 180191.

Berlyne, D. E. (1960). Conflict, arousal, and curiosity.

Blau, P. M. (1964). Exchange and power in social life. Transaction Publishers.

Butler, J. K. (1991). Toward understanding and measuring conditions of trust: Evolution of a conditions of trust inventory. Journal of Management, 17(3), 643-663.

Cacioppo, J. T., Petty, R. E., Feinstein, J. A., \& Jarvis, W. B. G. (1996). Dispositional differences in cognitive motivation: The life and times of individuals varying in need for cognition. Psychological Bulletin, 119(2), 197-253.

Chou, H. W., Lin, Y. H., Chang, H. H., \& Chuang, W. W. (2013). Transformational Leadership and Team Performance. SAGE Open, 3(3), 1-10.

Cook, J., \& Wall, T. (1980). New work attitude measures 
of trust, organizational commitment and personal need non-fulfilment. Journal of Occupational Psychology, 53(1), 39-52.

Day, H. I. (1971). Intrinsic motivation: A new direction in education.

Dirks, K. T. (2000). Trust in leadership and team performance: evidence from NCAA basketball. Journal of Applied Psychology, 85(6), 1004-1012.

Eisenberger, R., Fasolo, P., \& Davis-LaMastro, V. (1990). Perceived organizational support and employee diligence, commitment, and innovation. Journal of Applied Psychology, 75(1), 51-57.

Ford, C. M. (1996). A theory of individual creative action in multiple social domains. Academy of Management Review, 21(4), 1112-1142.

Gill, H., Boies, K., Finegan, J. E., \& McNally, J. (2005). Antecedents of trust: Establishing a boundary condition for the relation between propensity to trust and intention to trust. Journal of Business and Psychology, 19(3), 287-302.

Goris, J. R., Vaught, B. C., \& Pettit Jr, J. D. (2003). Effects of trust in superiors and influence of superiors on the association between individual-job congruence and job performance/satisfaction. Journal of Business and Psychology, 17(3), 327-343.

Hackman, J. R. (2002). Leading teams: Setting the stage for great performances. Harvard Business Press.

Hackman, J. R., Walton, R. E., \& Goodman, P. S. (1986). Leading groups in organizations. Designing effective work groups.

Kanter, R. M. (1988). Three tiers for innovation research. Communication Research, 15(5), 509-523.

Kashdan, T. B., Rose, P., \& Fincham, F. D. (2004). Curiosity and exploration: Facilitating positive subjective experiences and personal growth opportunities. Journal of Personality Assessment, 82(3), 291-305.

Kozlowski, S. W., Gully, S. M., Nason, E. R., \& Smith, E. M. (1999). Developing adaptive teams: A theory of compilation and performance across levels and time. Pulakos (Eds.), The changing nature of performance: Implications for staffing, motivation, and development, 240-292.

Kramer, R. M. (1999). Trust and distrust in organizations: Emerging perspectives, enduring questions. Annual Review of Psychology, 50(1), 569-598.

Leuba, C. (1958). A new look at curiosity and creativity. The Journal of Higher Education, 29(3), 132-140.

Litman, J. A. (2008). Interest and deprivation factors of epistemic curiosity. Personality and Individual Differences, 44(7), 1585-1595.

Litman, J. A., \& Spielberger, C. D. (2003). Measuring epistemic curiosity and its diversive and specific components. Journal of Personality Assessment, 80(1), 75-86.
Loewenstein, G. (1994). The psychology of curiosity: A review and reinterpretation. Psychological Bulletin, 116(1), 75-98.

Lubart, T. I. (2001). Models of the creative process: Past, present and future. Creativity Research Journal, 13(3-4), 295-308.

Madjar, N., Oldham, G. R., \& Pratt, M. G. (2002). There's no place like home? The contributions of work and nonwork creativity support to employees' creative performance. Academy of Management Journal, 45(4), 757-767.

March, J. G., \& Simon, H. A. (1958). Organizations.

Mayer, R. C., \& Davis, J. H. (1999). The effect of the performance appraisal system on trust for management: A field quasi-experiment. Journal of Applied Psychology, 84(1), 123-136.

Mayer, R. C., Davis, J. H., \& Schoorman, F. D. (1995). An integrative model of organizational trust. Academy of Management Review, 20(3), 709-734.

Mayer, R. C., Davis, J. H., \& Schoorman, F. D. (1995). An integrative model of organizational trust. Academy of Management Review, 20(3), 709-734.

McAllister, D. J. (1995). Affect-and cognition-based trust as foundations for interpersonal cooperation in organizations. Academy of Management Journal, 38(1), 24-59.

McCauley, D. P., \& Kuhnert, K. W. (1992). A theoretical review and empirical investigatiomn of employee trust in management. Public Administration Quarterly, 16(2), 265-284.

McKnight, D. H., \& Chervany, N. L. (1996). The meanings of trust.

Moorman, C., \& Miner, A. S. (1997). The impact of organizational memory on new product performance and creativity. Journal of Marketing Research, 34(1), 91-106.

Mussel, P. (2010). Epistemic curiosity and related constructs: Lacking evidence of discriminant validity. Personality and Individual Differences, 49(5), 506-510.

Olson, K., Camp, C., \& Fuller, D. (1984). Curiosity and need for cognition. Psychological Reports, 54(1), 71-74.

Parayitam, S., \& Dooley, R. S. (2007). The relationship between conflict and decision outcomes: Moderating effects of cognitive-and affect-based trust in strategic decision-making teams. International Journal of Conflict Management, 18(1), 42-73.

Podsakoff, P. M., MacKenzie, S. B., Moorman, R. H., \& Fetter, R. (1990). Transformational leader behaviors and their effects on followers' trust in leader, satisfaction, and organizational citizenship behaviors. The Leadership Quarterly, 1(2), 107-142.

Ranaweera, C., \& Prabhu, J. (2003). The influence 
of satisfaction, trust and switching barriers on customer retention in a continuous purchasing setting. International Journal of Service Industry Management, 14(4), 374-395.

Redmond, M. R., Mumford, M. D., \& Teach, R. (1993). Putting creativity to work: Effects of leader behavior on subordinate creativity. Organizational Behavior and Human Decision Processes, 55(1), 120-151.

Rousseau, D. M., Sitkin, S. B., Burt, R. S., \& Camerer, C. (1998). Not so different after all: A cross-discipline view of trust. Academy of Management Review, 23(3), 393-404.

Shalley, C. E., \& Gilson, L. L. (2004). What leaders need to know: A review of social and contextual factors that can foster or hinder creativity. The Leadership Quarterly, 15(1), 33-53.

Shalley, C. E., Zhou, J., \& Oldham, G. R. (2004). The effects of personal and contextual characteristics on creativity: where should we go from here?. Journal of Management, 30(6), 933-958.

Simmons, A. L., \& Sower, V. E. (2012). Leadership sagacity and its relationship with individual creative performance and innovation. European Journal of Innovation Management, 15(3), 298-309.

Staw, B. M. (1990). An evolutionary approach to creativity and innovation.

Tierney, P., \& Farmer, S. M. (2004). The Pygmalion process and employee creativity. Journal of Management, 30(3), 413-432.

Tuten, T. L., \& Bosnjak, M. (2001). Understanding differences in web usage: The role of need for cognition and the five factor model of personality. Social Behavior and Personality: An International Journal, 29(4), 391-398.

Van de Ven, A. H. (1986). Central problems in the management of innovation. Management Science, 32(5), 590-607.

Vissers, G., \& Dankbaar, B. (2002). Creativity in multidisciplinary new product development teams. Creativity and Innovation Management, 11(1), 3142.

Wiggins, J. S., Trapnell, P. D., Hogan, R., Johnson, J., \& Briggs, S. (1997). Handbook of personality psychology.

Woodman, R. W., Sawyer, J. E., \& Griffin, R. W. (1993). Toward a theory of organizational creativity. Academy of Management Review, 18(2), 293-321.

Yi, X., Hu, W., Plucker, J. A., \& McWilliams, J. (2013). Is there a developmental slump in creativity in China? The relationship between organizational climate and creativity development in Chinese adolescents. The Journal of Creative Behavior, 47(1), 22-40.

Zenasni, F., Besançon, M., \& Lubart, T. (2008). Creativity and tolerance of ambiguity: An empirical study. The Journal of Creative Behavior, 42(1), 61-73.

Zhang, X., \& Bartol, K. M. (2010). The influence of creative process engagement on employee creative performance and overall job performance: a curvilinear assessment. Journal of Applied Psychology, 95(5), 862-873. 